\title{
A Novel Scanning Land Mine Detector Based on the Technique of Neutron Back Scattering Imaging
}

\author{
Victor Bom, A. M. Osman, and A. M. Abdel Monem
}

\begin{abstract}
The neutron back-scattering (NBS) technique is a well established method to find hydrogen in objects. It can be applied in land mine detection taking advantage of the fact that land mines are abundant in hydrogen.

The NBS technique is suitable for land mine scanning e.g., seeking for land mines with a moving detector system, because of the high speed of operation. Scan speeds up to $800 \mathrm{~mm} / \mathrm{s}$ are reported here depending on the intensity of the neutron source, the mine size and the depth at which the mine is buried.
\end{abstract}

Index Terms-Explosives detection, land mines, neutron detector.

\section{INTRODUCTION}

\section{A. History of Land Mines}

$\mathbf{T}$ HE origin of the word 'land mine' stems from the technique of sapping, used in siege operations indicating the digging of trenches or 'saps of approach' to safely advance troops. Saps also were tunnels made underneath enemy fortifications thereby 'under-mining' fortress walls, castles etc. These fortifications were then destroyed by letting the tunnels or 'mines' collapse, first naturally and later by means of explosives.

The first written reference to gunpowder or 'black powder' used in early land mines is probably a Chinese text tentatively dated to mid-800 [1]. Gunpowder was used by Samuel Zimmermann, a military engineer at Augsburg, in 1573 to make the first anti-personnel mine called the 'fladdermine': a black powder bomb buried in a shallow well and covered with scrap metal and/or gravel activated by a snaphane or flintlock mechanism connected to a tripwire on the surface [2]. Mechanically fused anti-personnel land mines using high explosives were first used by Confederate troops during the U.S. Civil War Battle of Yorktown in 1862 [3]. During the second world war, land mines were used to hinder tank movements. The advancing troops soon found however that they could remove these anti-tank mines by hand. This led to anti-personnel mines being laid close to the anti-tank mine to protect them [4].

Egypt is the country with the highest number of land mines: estimated at 23 million. They originate mainly from the World

Manuscript received August 29, 2007; revised January 23, 2008. This work was supported by the IAEA, which supported the research into humanitarian demining at the Nuclear Research Center of the Egyptian Atomic Energy Authority.

V. Bom is with the Delft University of Technology, 2629 JB Delft, The Netherlands (e-mail: V.R.Bom@TUDelft.nl).

A. M. Osman and A. M. A. Monem are with the Reactor and Neutron Physics Department, Nuclear Research Center, Atomic Energy Authority, Cairo, Egypt.

Digital Object Identifier 10.1109/TNS.2008.918741
War II battles along the coast but also from various border conflicts with neighbor countries. U.N. estimates [5] show that about half of all land mines are found in the arid countries in the middle east and the north of Africa.

The real problem in demining is to locate the mines in the ground [6]. Their very small size, especially of the anti-personnel mines, makes them difficult to detect. Humanitarian demining at present is almost entirely done using metal detectors and so called prodders: little sticks used to prick the ground to 'feel' a mine. These methods result in a slow, dangerous and costly demining process.

Although some of the modern methods such as Electro Magnetic Induction (e.g., metal detector) and Ground Penetrating Radar are effective for locating metal like anomalies, they can not be used to identify the anomalies and to confirm the presence of a land mine [7].

\section{B. Neutron Back Scattering Principles}

The neutron back-scattering (NBS) technique is a well established method to show the presence of hydrogen. It is in use for instance, to monitor water levels in large containers [8], [9] or to determine the moisture level in building materials [10]. By the end of the 20th century, an international effort was made to introduce nuclear techniques into the search for buried land mines and in 1999 NBS was first introduced for demining purposes by Brooks [11].

The NBS demining technique [12]-[15] is based on the high concentration of hydrogen in land mines, which is present in the explosive chemicals, but also in the plastic parts of the land mine e.g., the casing.

A NBS detector operates by irradiating the soil with highenergy $(\mathrm{MeV})$ neutrons. The neutrons lose energy by scattering from atoms in the soil and become thermal after a number of collisions. A thermal neutron detector monitors the low-energy neutron flux coming back from the soil.

The thermalization process takes many fewer collisions when scattering from hydrogen as compared to other elements. The concentration of thermal neutrons in hydrogenous regions of the soil will therefore be relatively high. The thermal neutron flux at the surface will thus show an increase above spots which are relatively rich in hydrogen. Such thermal neutron 'hot spots' may indicate a land mine.

The main advantage of the NBS method is the high speed of operation which is possible. Mine detection times of less than a second are feasible when a sufficiently strong neutron source is used [16], [17]. NBS based systems can therefore be used to scan an area for land mines. 


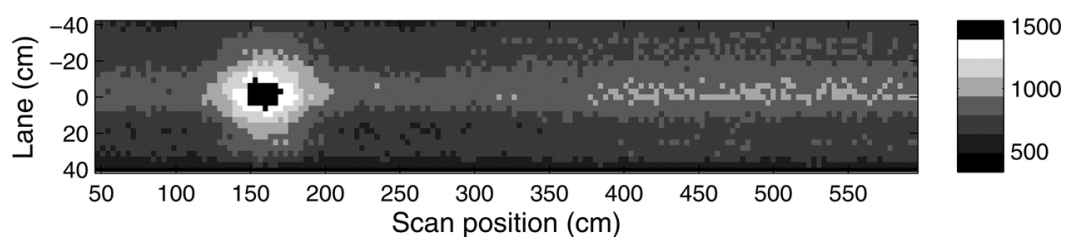

Fig. 1. The measured signal of an anti tank mine in the center at $10 \mathrm{~cm}$ depth. Detector-ground-surface distance: $10 \mathrm{~cm}$. Scan speed: $1 \mathrm{~mm} / \mathrm{s},{ }^{252} \mathrm{Cf}$ source: $1.6 \cdot 10^{5} \mathrm{n} / \mathrm{s}$.

Other mine detection systems based on nuclear techniques, such as pulsed fast neutron analysis (PFNA) or thermal neutron analysis (TNA), show speeds of operation of the order of minutes. They are better suited as confirmation detectors to identify an already found buried object as a mine.

Additional advantages of NBS based devices over metal detectors or ground penetrating radar devices are: the insensitivities for rocks, stones and metal objects like shells or cartridges of fire arms. This is an important advantage because former combat areas generally contain huge amounts of metal debris. The ratio between scrap metal pieces and mines may be well above 1000 [18]. The possibility to find fully metal-free mines is also important since such mines are used increasingly.

The main limitation of the NBS method lies in the sensitivity to soil moisture. The hydrogen content of a land mine is comparable to that of sand with a moisture level of $\approx 10 \%$ [19]-[22], resulting in a loss of contrast between the mine and its surroundings. The NBS method can therefore be applied most advantageously in arid countries such as Egypt, Lybia or in the Middle East.

NBS imaging uses a two-dimensional position sensitive neutron detector. A two dimensional distribution or image is obtained of the low-energy neutron radiation, which is emerging from the soil. A concentration of hydrogen shows up as a hot spot: a more or less circular area with a higher neutron radiation intensity as compared to the surroundings. The advantage of using a two dimensional image is that the sensitivity for mine detection is greatly enhanced in comparison to only monitoring the overall count rate. The two dimensional distribution is not a real image of the mine because scattering of the neutrons in the soil blurs the image resulting in hot spots which are always circular. The size of the spot has a weak dependence on the mine size and on the mine depth.

This paper describes the design and the properties of a NBS land mine detector applied in scan mode, such as the maximum scan speed in relation to the neutron source strength and the maximum depth of detection.

\section{The Delft Test Lane Facility}

The Delft test lane facility was especially constructed to test NBS demining systems in scan mode. The facility consists of a box of $3 \times 8 \times 1 \mathrm{~m}^{3}$ filled with sand. It is placed on $2 \times 2 \mathrm{~m}^{2}$ concrete plates, which have been laid on a $50 \mathrm{~cm}$ thick sand bed. The walls of the box are made of steel plates. The bottom of the box consists of an isolation layer of $5 \mathrm{~cm}$ thick foam plates, on top of which are: a layer of felt, an electric heating $\left(150 \mathrm{~W} / \mathrm{m}^{2}\right)$ blanket, a second felt layer and finally a layer of $1 \mathrm{~mm}$ thick aluminum plating.
The inside of this box is clad with thick plastic foil, as used for making garden pools, taped to the steel walls at $15 \mathrm{~cm}$ from the top. The box is loaded with 35 tons of river sand that has been dried and sifted (Grain size $0.1 \mathrm{~mm}$; SANSSIFT company). The box is filled to about $5 \mathrm{~cm}$ from the top thus covering the foil and tape completely. The sand is heated from the bottom to keep it as dry as possible and to simulate a desert condition. The sand temperature at the bottom is kept at approximately $26^{\circ} \mathrm{C}$.

The box is positioned inside an isolated and heated 'Quinset' hut with thin aluminum walls to minimize the scattering of neutrons from the surroundings.

The NBS detector and the associated electronics and sources are mounted on a frame, which can be moved by a stepping motor over rails fixed at the top of the box along the long sides. Flexible wiring such as signal cables and power lines run up to the frame through a cable support chain ('Staby Track'; http://www.flexiblehandling.co.uk/truckmobile.htm\#17). The frame may be loaded up to $75 \mathrm{~kg}$ and can move above the sand surface with speeds between $1 \mathrm{~mm} / \mathrm{s}$ and $1 \mathrm{~m} / \mathrm{s}$. The frame and detector may be operated locally from the hut or, in case of a strong neutron source or a neutron generator, remotely from a nearby shielded barrack.

The position of the frame with respect to the box is determined with a magnetic strip mounted alongside the box. A sensor attached to the frame counts the magnetized sections on the strip, which are passed over during the movements. This allows the electronics on the frame to determine the frame position with an accuracy better than $1 \mathrm{~mm}$.

\section{ESCALAD: THE EGYPT SCANNING LAND MINE DETECTOR}

A scanning NBS device is being developed at the Reactor and Neutron Physics Department of the Nuclear Research Center of the Egyptian Atomic Energy Authority, with the help of the Delft University of Technology and supported by the IAEA. The detector is based on the Delft DUNBID land mine system [17], [23], which was tested in Egypt [16], but which is not suitable for surface scanning. Scanning NBS land mine detectors do not exist at present.

\section{A. Design Considerations}

The size of the land mine hot spots is of the order of $75 \mathrm{~cm}$. This is evident from previous tests performed in Egypt [16] as well as from measurements in the Delft test lane such as the one shown in Fig. 1.

The hot spots are best recognized and located if they are fully contained within the measured images. This is illustrated by the images in Fig. 2, which have been simulated with the GEANT4 package, and which show the number of neutrons detected in 

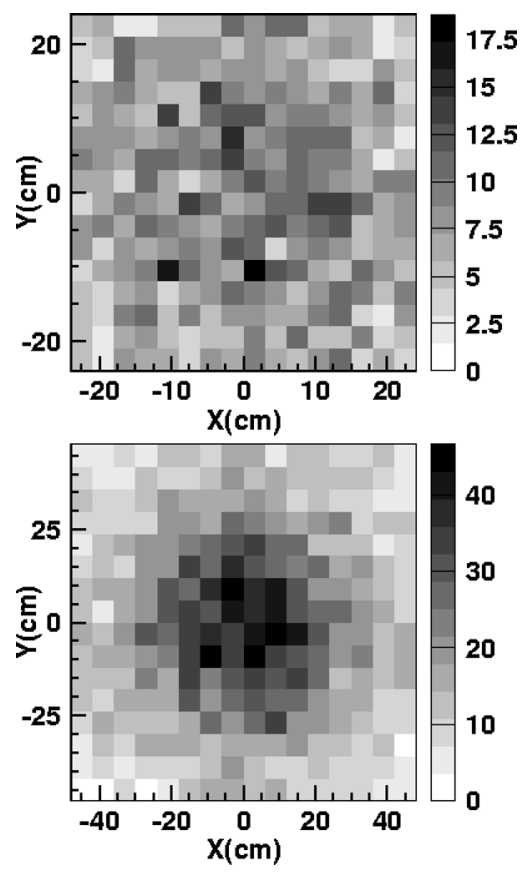

Fig. 2. Simulation of the signal of an anti tank mine in dry sand at $15 \mathrm{~cm}$ depth as measured by a stationary detector. Detector-ground-surface distance: $10 \mathrm{~cm}$. Mono-energetic neutrons of $2.45 \mathrm{MeV}$ (DD fusion source). Top: as seen by a $50 \times 50 \mathrm{~cm}^{2}$ detector; bottom: signal in a $100 \times 100 \mathrm{~cm}^{2}$ detector.

a plane above an anti tank mine as function of the position in the plane, for two plane sizes: $50 \times 50 \mathrm{~cm}^{2}$ and $100 \times 100 \mathrm{~cm}^{2}$. The pixel gray value indicates the number of detected neutrons. The presence of the hot spot can hardly be established for the smaller plane size. The detector size perpendicular to the scan direction has therefore been set to $1 \mathrm{~m}$.

The size of the detector in the scan direction could be small since the image in the scan direction is built by moving the detector over a sufficiently long distance. However, the detector sensitivity at a certain primary neutron emission rate can be improved by using a larger size (see Fig. 3). The improvement will however level off at larger sizes because of the increasing distance from the neutron source. The detector size in the scan direction has been set to $50 \mathrm{~cm}$ weighing the decreasing sensitivity gain against the increasing costs of a larger detector.

\section{B. Construction}

The Egypt SCAnning LAnd mine Detector (ESCALAD) consists of $16{ }^{3} \mathrm{He}$ proportional counter tubes with resistive wires (from Reuter-Stokes, Inc. Edison Park, 8499 Darrow Road Twinsburg, OH 44087-2398), mounted parallel in a flat encasing of $142 \times 117 \times 15 \mathrm{~cm}^{3}$, perpendicular to the direction of scanning. ${ }^{3} \mathrm{He}$ tubes are sensitive mainly to thermal neutrons through the reaction: ${ }^{3} \mathrm{He}+n \rightarrow p+t+764 \mathrm{keV}$. The specifications of the tubes are: length $100 \mathrm{~cm}$, diameter 2.5 $\mathrm{cm}$ and ${ }^{3} \mathrm{He}$ pressure $10 \mathrm{bar}$. The neutron detection efficiency varies from 1 for thermal energy down to $10^{-4}$ for neutrons in the $\mathrm{MeV}$ energy range. The tubes are mounted in two banks of 8 tubes; tube pitch within a bank: $27.8 \mathrm{~mm}$, bank separation: $237.6 \mathrm{~mm}$ between the adjacent tubes axes. This separation allows for the placement of radioactive neutron sources or of a

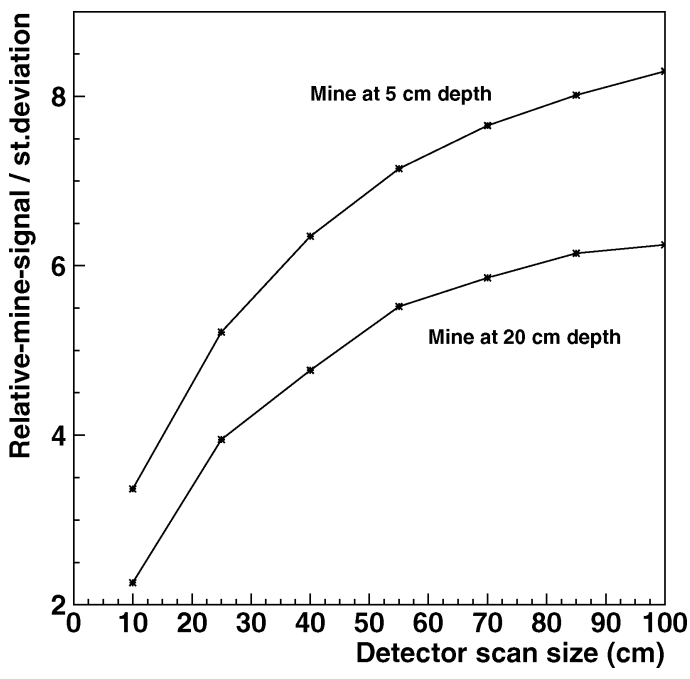

Fig. 3. Simulation of a scan over an anti tank mine in dry sand. Detector-ground-surface distance: $10 \mathrm{~cm} .{ }^{252} \mathrm{Cf}$ neutron energy distribution. The net hot spot content divided by its standard deviation is plotted as function of the detector size in the scan direction.

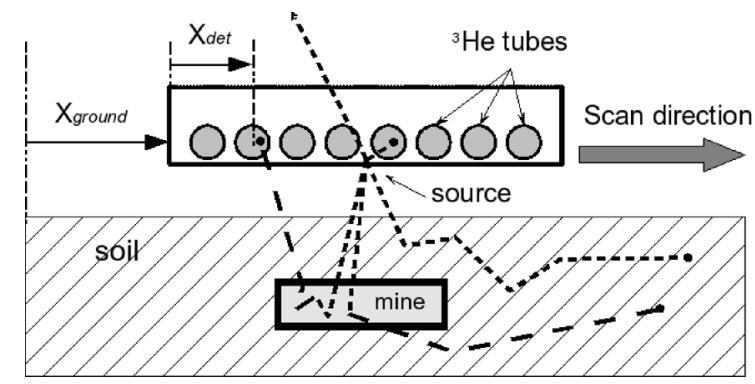

Fig. 4. The cross section of a detector with $8^{3}$ He tubes is shown schematically while scanning over a land mine. Fast neutrons (short dashed tracks) emerge from the source, are scattered in the mine and reappear at the soil surface as thermal neutrons (long dashed tracks). The intensity distribution over the soil surface is formed while scanning using the neutron hit coordinate determined from the neutron tube position Xdet and the detector position Xground. The coordinate perpendicular to the scan direction is determined by charge division.

neutron generator in the center of the detector. Bank separation is a compromise between two effects:

- the detection sensitivity decreases for an increasing separation distance because of the increase of the path length: source-mine-detector;

- bull; the 'fast neutron background' increases for smaller separation distances leading to a worse signal-to-background ratio. This type of background is caused by high-energy neutrons, which come straight from the source.

The total sensitive detector area is about $100 \times 44 \mathrm{~cm}^{2}$.

The system is being constructed at the Delft University. First tests are done in the Delft test lane (Section II).

\section{Collection of the Image}

The detector is mounted on a frame allowing it to move or scan horizontally above the ground at a standoff distance of 10 $\mathrm{cm}$ (see Fig. 4). The neutron counts are processed during the movement and are used to build an image of the thermal neutron flux, which is emerging from the ground. 


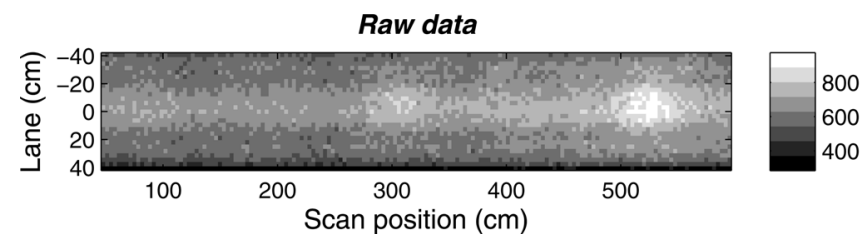

Fast neutron background removed

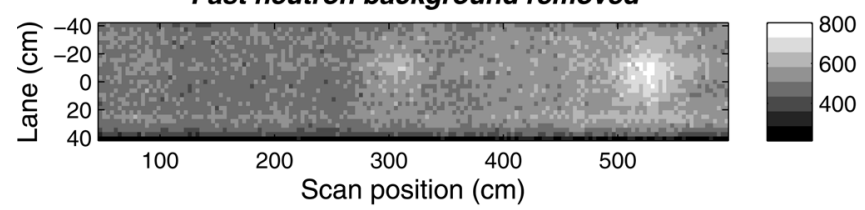

All backgrounds removed
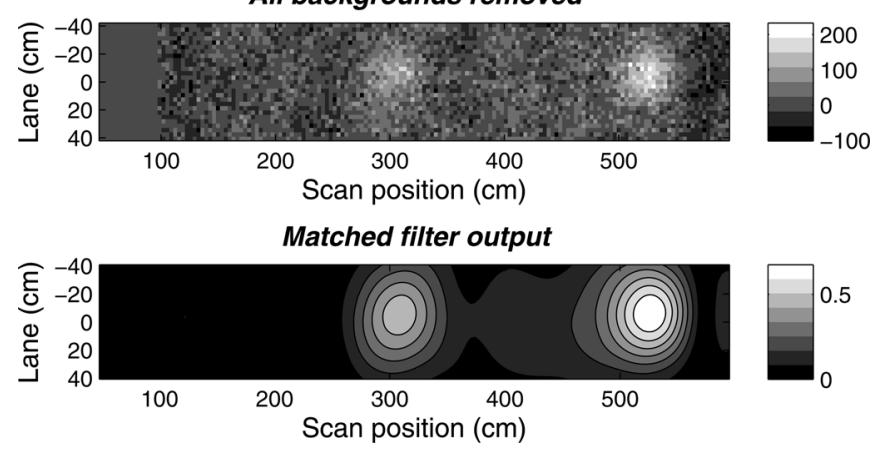

Fig. 5. The measured signals of two anti personnel mines at $10 \mathrm{~cm}$ depth: a nylon mine at position 300 and a polyethylene one at 525 . Detector-groundsurface distance: $10 \mathrm{~cm}$. Scan speed: $1 \mathrm{~mm} / \mathrm{s},{ }^{252} \mathrm{Cf}$ source: $1.6 \cdot 10^{5} \mathrm{n} / \mathrm{s}$.

The coordinate of a neutron hit in the direction of scanning with respect to a ground related reference frame is determined from the position of the tube being hit in the encasing and the position of the encasing with respect to the ground. The coordinate along the tubes is determined by charge division performed by the electronics (Mesytec GmbH \& Co., KG Wernher-vonBraun-Str. 1, 85640 Putzbrunn, Germany). Counts are stored according to the measured positions in a $32 \times 256$ array of pixels with a pixel size of $3.3 \times 3.4 \mathrm{~cm}^{2}$. The first dimension denotes the direction along the tube thus perpendicular to the scan direction; the second one denotes the direction of scanning. The overall background count rate is about $500 \mathrm{c} / \mathrm{s}$ for a ${ }^{252} \mathrm{Cf}$ source with an emission rate of $1.6 \cdot 10^{5} \mathrm{n} / \mathrm{s}$ and a detector-ground-surface distance of $10 \mathrm{~cm}$. The maximum count rate possible with the current electronics is $2 \cdot 10^{5} \mathrm{c} / \mathrm{s}$ which corresponds to a maximum source strength of about $6 \cdot 10^{7} \mathrm{n} / \mathrm{s}$.

Each tube in turn spends a time of $3.4 / v$ s above a row of pixels, with $v(\mathrm{~cm} / \mathrm{s})$ the scan speed. The total measurement time for the detector tubes to pass completely over a row of pixels, the 'pass-over-time', thus is: $16(3.4 / v)$.

\section{Image Analysis}

An example of a raw image of a mine scan is shown in Fig. 1 and in the top image of Fig. 5. The signals from the ${ }^{3} \mathrm{He}$ tubes for neutron hits near the tube ends are too small for the electronics to calculate a good position. Therefore, the figures shows a scan lane of only $80 \mathrm{~cm}$ width. The mine signal is very strong for the anti tank mine (Fig. 1) but for deeper lying and/or smaller mines and/or at greater scan speeds the mine will give a weaker signal. The mine signal will disappear in the statistical counting noise for conditions near the limit of detection and will no longer be perceivable by eye.

The examples also show a slowly increasing intensity towards higher scan positions. This is due to a slightly higher sand level at the end of the test lane and a correspondingly smaller detector-ground-surface distance. The band of raised intensity running through the image around lane position 0 is due to those positions being closest to the source.

The raw data has three components:

1) the signal from the mine (if present);

2) a contribution caused by neutrons scattering from the soil;

3) a contribution from fast neutrons, which hit the detector without having entered the soil.

The latter two components constitute a background in the image, which must be subtracted for proper mine detection.

A row of image pixels perpendicular to the scan direction will simply be called: 'a pixel row', while a row of image pixels along the scan direction will be called 'a pixel line'.

The first step in the analysis of the images is the application of a 'fast neutron background' correction. The fast neutron background is an intrinsic system property. It has been measured by placing the detector about $1.5 \mathrm{~m}$ above the soil and registering the count rate distribution along each tube. The correction is done by summing the fast neutron measurement along the scan direction and subtracting the result from the pixel rows in the raw image after normalization to the measurement time. The effect of this correction is to remove the central high intensity band and to increase relatively the intensity at the edges of the detector. This is shown in Fig. 5 by comparison of the two top pictures.

The next step in the image analysis consists in estimating the background at the mine position due to the soil itself. The mine signal would be best obtained by subtracting a measurement without the mine from the measurement with the mine but this is of course not possible in practice.

The background due to the soil at a certain pixel is estimated by extrapolating the pixel data from a window along the pixel line preceding the pixel. The extrapolation is done by taking the average value of the pixel data within the window. The background over the total image is estimated by shifting the window over the image in the direction of the scan. When the pixel data in a narrow 'look-ahead' window in front of the background window are consistently above the so determined background it is concluded that the background window is moving into the area of a mine signal. The pixel data from such a mine signal area are not used for background estimation.

The background estimation procedure described here can in principle be carried out during the measurement because it only relies on pixel data which has already been obtained, and therefore allows for scans of indefinite length. The procedure acts as a low pass filter for the spatial frequencies in the pixel data: rapid fluctuations will be damped by the averaging process. The filter cut off frequency is determined by the width of the window. A narrow window allows the background to fluctuate more rapidly than a wide window. We found that a window width of $35 \mathrm{~cm}$ gave the best overall results. A mine shows up as a hot spot in the image thus corrected. Such a hot spot is called the 'mine signal'. 
TABLE I

Specifications of the Mines Used for Testing. The Chemical Composition of the Fillings are Melamine: $\mathrm{C}_{3} \mathrm{~N}_{3}\left(\mathrm{NH}_{2}\right)_{3}, \mathrm{Nylon} \mathrm{C}_{6} \mathrm{H}_{11} \mathrm{NO}$, PVC: $\mathrm{C}_{2} \mathrm{H}_{3} \mathrm{Cl}$ POLYETHYLENE: $\left(\mathrm{C}_{2} \mathrm{H}_{4}\right)_{n}$

\begin{tabular}{rccl}
\hline mine & size $(\mathrm{cm} \times \mathrm{cm})$ & No. of H-atoms & Description \\
\hline AT & $\varnothing 28 \times 6$ & $1.1 .10^{26}$ & PVC casing filled with $2 \mathrm{~kg}$ melamine \\
AP: PE & $\varnothing 6 \times 4$ & $9.2 .10^{24}$ & massive polyethylene \\
AP: Nylon & $\varnothing 6 \times 4$ & $7.4 .10^{24}$ & massive Nylon
\end{tabular}

The third step in the analysis consists in recognizing and locating the hot spots and distinguishing them from background variations. We applied the method of 'matched filtering' [24]. This method entails a convolution of the image with a template of the sought mine signal. The output of the convolution will be high when the image does contain such a signal. A mine is detected at some position when the matched filter output at that position is above a threshold value.

The template was obtained by isolating the mine signal from a measurement with high statistics of an anti tank mine at small depth, after removal of the background. The template was lightly filtered with a Gaussian filter to diminish the counting noise and normalized to have a total content of 1.0.

All image analysis procedures have been realized in MATLAB code. Matched filtering is done by multiplying the Fourier transforms of the image and the over $180^{\circ}$ rotated template. The matched filter output is obtained as the real part of inverse Fourier transform of this product. This procedure is mathematically equivalent to the convolution operation mentioned above but has the advantage of a fast computation because of the availability of very efficient Fourier transformation routines.

Mines are less well detected when they are located too far off center. The matched filter output will be lower in such a case because the mine signal will not contribute fully to the convolution calculation as it will be partly outside the image.

\section{Measurements}

The primary high-energy neutrons were obtained from a variety of sources:

- a radioactive ${ }^{252} \mathrm{Cf}$ source with a strength of about 1.6 . $10^{5} \mathrm{n} / \mathrm{s}$;

- a DD neutron generator emitting $2 \cdot 10^{6} \mathrm{n} / \mathrm{s}$;

- a radioactive PuBe source with strength $6 \cdot 10^{6} \mathrm{n} / \mathrm{s}$.

The point of neutron emission by a source placed in the detector encasing is around $12 \mathrm{~cm}$ from the ground. The standoff distance between the bottom of the detector encasing and the sand surface was roughly $10 \mathrm{~cm}$. The test mines used are listed in Table I. The depth of a buried mine is defined as the distance between the soil surface and the top of the mine. The sand was just left as it was after burying the mines and no effort was done to level the sand surface. A moisture level below $0.5 \%$ was determined from a sand sample by comparison of the weight before and after heating to $110^{\circ} \mathrm{C}$ for 15 hours.

Fig. 5 shows the results for a scan of the two anti personnel mines from Table I at a depth of $10 \mathrm{~cm}$ using the $\mathrm{Cf}$ source and a scan speed of $1 \mathrm{~mm} / \mathrm{s}$. The image shows the scan between 0 and $6 \mathrm{~m}$ and with a width of $80 \mathrm{~cm}$. The detector has to pass completely over a position to measure the neutron flux at that position therefore the effective length of a scan is smaller by the

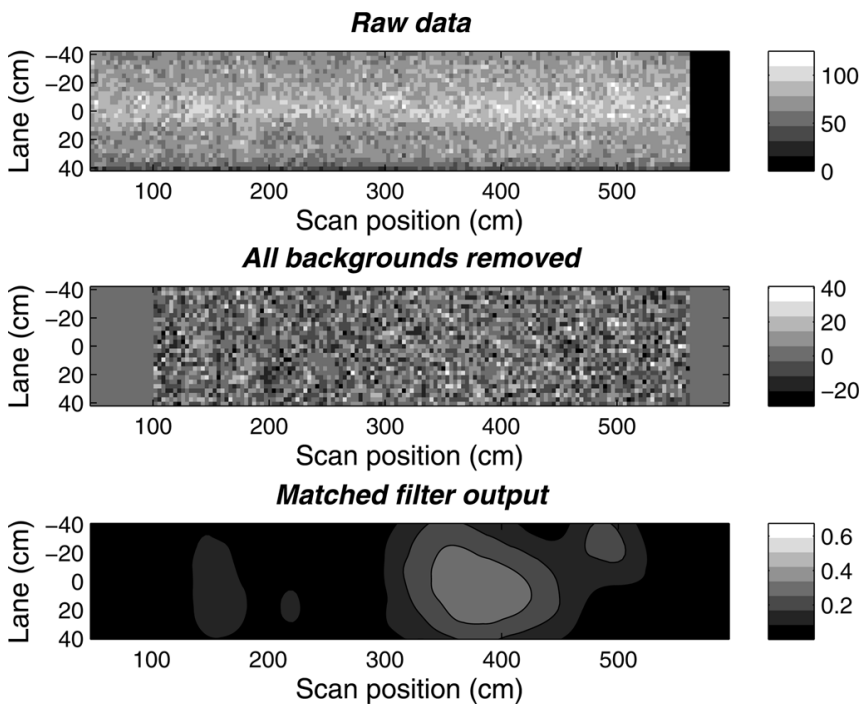

Fig. 6. The measured signal without mines. The intensity scales of the bottom images of this figure and Fig. 5 are the same. Scan speed: $10 \mathrm{~mm} / \mathrm{s},{ }^{252} \mathrm{Cf}$ source: $1.6 \cdot 10^{5} \mathrm{n} / \mathrm{s}$.

detector size in the scan direction $(\approx 65 \mathrm{~cm})$ than the distance over which the detector moved.

The pixel counts as obtained from data acquisition are shown in the top image. The mine at $300 \mathrm{~cm}$ is only just distinguishable in this raw image because anti personnel mines at this depth are near the limit of detection. The visibility of both mines is enhanced by removal of the backgrounds due to the fast neutrons and to soil scattering and the susbsequent application of a light Gaussian filter as shown in the third image from the top. The shape of the mine signal is approximately circular with a diameter of about $70 \mathrm{~cm}$. The output of the matched filter is shown in the bottom image of the figure. All matched filter data are normalized to $10^{6}$ neutrons emitted in the pass-over-time.

The matched filter output should be compared to the result of a scan without a mine, see Fig. 6 . The pixel data in the middle image varies around zero between -10 and +10 as expected for statistical counting noise. The matched filter output has a maximum of 0.35 at scan position 375 . The maximum matched filter signal for background under the given circumstances can therefore be set to 0.4. Signals above this limit will be interpreted as a mine; while mines will not be recognized as their signal falls below this limit leading to false negatives. The matched filter output of both the polyethylene and the nylon mine in Fig. 5 ( 0.77 and 0.55 respectively) are above the detection limit.

The characteristic shape of a mine signal is circular even for tilted mines or square mines because of the scattering of the neutrons on their way to the surface. An asymmetric structure with a size of the order of the normal mine signal $(\approx 70 \mathrm{~cm})$ might show a deviation from the circular shape if buried at a shallow 


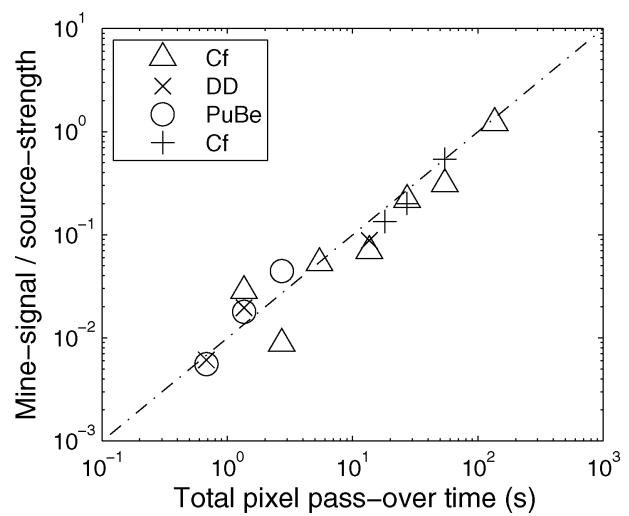

Fig. 7. The measured relative mine signal versus the time it takes for the detector to pass over a pixel. Mine depth: $10 \mathrm{~cm},{ }^{252} \mathrm{Cf}$ source: $1.6 \cdot 10^{5} \mathrm{n} / \mathrm{s}$, DD source: $2 \cdot 10^{6} \mathrm{n} / \mathrm{s}$, PuBe source: $6 \cdot 10^{6} \mathrm{n} / \mathrm{s}$. The dot-dashed line displays the linear relation: signal $=$ time $/ 100$.

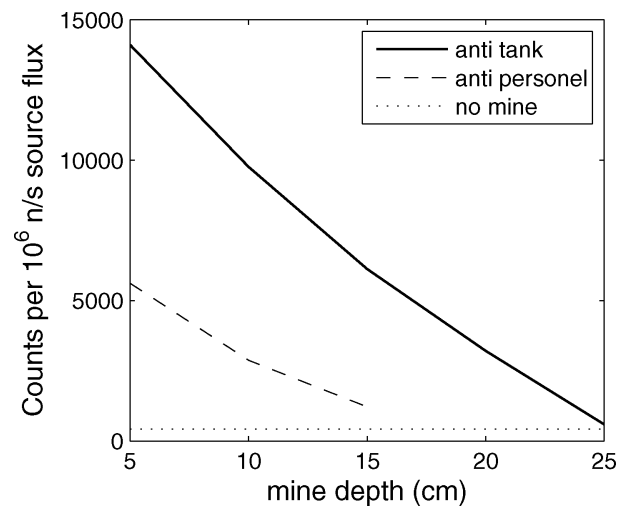

Fig. 8. The measured signal versus mine depth. Scan speed: $1 \mathrm{~mm} / \mathrm{s},{ }^{252} \mathrm{Cf}$ source: $1.6 \cdot 10^{5} \mathrm{n} / \mathrm{s}$.

depth. It would be interpreted as a mine because it would give a strong signal.

\section{A. Scan Speed}

The total number of counts in the mine signal can be obtained by summation of the pixel contents in a circular area around the mine position from of the data corrected for background. The mine signal of the anti tank mine at a depth of $10 \mathrm{~cm}$ as function of the pass-over-time is shown in Fig. 7 for various source strengths and scan speeds. The number of counts is proportional to the measurement time as is to be expected, following the relation: Mine-signal $=0.01 \times$ sourcestrength $\times$ pass-over-time. This relation is represented in the figure by the dot-dashed line. This means that $1 \%$ of the primary high-energy neutrons is detected after scattering back from the mine.

\section{B. Maximum Depth}

The total number of counts in the mine signal normalized to a source strength of $10^{6} \mathrm{n} / \mathrm{s}$ is shown in Fig. 8 as a function of mine depth. The dotted line shows the number of counts in the background, obtained from Fig. 6. The functional behavior of the lines is similar to previously reported simulations and measurements [19], [25], [26]. The maximum depth at which mines can be found under the circumstances of the tests can be read from the figure as the depth at which the lines cross the background line. This maximum depth is $15 \mathrm{~cm}$ for anti personnel mines, and $25 \mathrm{~cm}$ for anti tank mines.

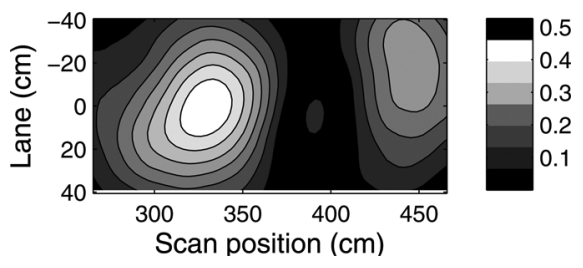

Fig. 9. The matched filter output of the anti tank mine at $25 \mathrm{~cm}$ depth. Scan speed: $1.8 \mathrm{~m} / \mathrm{min},{ }^{252} \mathrm{Cf}$ source: $1.6 \cdot 10^{5} \mathrm{n} / \mathrm{s}$. The artifact at 450 is interpreted as a background fluctuation because of its shape and its low intensity.

A mine can only be detected if the mine signal can be distinguished from the background fluctuations. The observational limit of the least size of mine and the greatest detection depth is therefore determined by the size and intensity of the background structures in the image. This limit is independent of the source strength as long as the counting statistics are well below the background fluctuations.

\section{CONCLUSION}

The scan speed can already be in the meter/minute range with a relatively small neutron source as illustrated by Fig. 9 .

This test indicates that anti-tank mines can be found in the Delft test lane at depths of $25 \mathrm{~cm}$ at a speed of $30 \mathrm{~mm} / \mathrm{s}$ using a $\mathrm{Cf}$ source of $1.6 \cdot 10^{5} \mathrm{n} / \mathrm{s}$. Anti-personnel mines have been found up to depths of $15 \mathrm{~cm}$. These limits may be different when the detector is used on other soils.

A mine is best recognized by the software when the mine signal is fully contained in the image. This is the case for mines which are not more than about $15 \mathrm{~cm}$ off center, given the approximate size of the mine signal of $\approx 75 \mathrm{~cm}$ and the size of the detector of $100 \mathrm{~cm}$. In addition, mines which are located further from the centrally placed source will give weaker signals. The width of the strip being scanned is therefore about $30 \mathrm{~cm}$.

The identification of a hot spot appearing outside this strip as a mine is less reliable because the signal is partly outside the image. Large mines giving a strong signal may still be detected in this case but smaller and deeper lying mines may be interpreted as noise and go unnoticed.

A wider scan strip might be realized by increasing the detector width. A sufficient level of radiation intensity towards the edges of the detector may be reached by using multiple neutron sources.

An average scan covers an area of approximately $1 \times 6 \mathrm{~m}^{2}$. AP and AT mines can be reliably detected up to depths of 25 and $15 \mathrm{~cm}$ respectively in the much smaller area of $0.30 \times 6 \mathrm{~m}^{2}$. The expected maximum mine detection speed is about $500 \mathrm{~m}^{2} /$ day, based on a 5 hour working day and a neutron emission rate of $1.6 \cdot 10^{7} \mathrm{n} / \mathrm{s}$ and a scan speed of $100 \mathrm{~mm} / \mathrm{s}$. This compares favorably to the reported speed of manual demining of 15-20 $\mathrm{m}^{2} /$ day [27], [28].

The detection system needs to be placed on a cart or trolley when applied in the field. The trolley could be manned or remote controlled. The radiation dose at the operators position in case of a manned trolley has been calculated to be around $0.1 \mu \mathrm{Sv} / \mathrm{h}$ for a $\mathrm{AmBe}$ neutron source of $10^{6} \mathrm{n} / \mathrm{s}$ at $3.5 \mathrm{~m}$ from the operator without applying shielding. Dose measurements have confirmed this calculation. 


\section{REFERENCES}

[1] K. W. Chase, Firearms: A Global History to 1700. Cambridge, U.K.: Cambridge Univ. Press, 2003.

[2] M. William and C. Schneck, The Origins of Military Mines, Part I Appeared in Engineer Bulletin, 1998 [Online]. Available: http://www.fas. org/man/dod-101/sys/land/docs/980700-schneck.htm

[3] R. L. Roy and S. K. Friesen, Historical Uses of Anti-Personnel Landmines: Impact on Land Force Operations, Department of National Defense, Canada, 1999 [Online]. Available: www.reviewconference.org/fileadmin/pdf/review_conference/regional_conference/amman/Historical_Uses_Study.pdf

[4] C. Bruschini and B. Gros, "A survey of research on sensor technology for landmine detectione," J. Human. Demin., vol. 2.1, Feb. 1998.

[5] Land Mines: Hidden Killers, UNICEF [Online]. Available: http://www.unicef.org/sowc96pk/hidekill.htm

[6] K. Eblagh, "Practical problems in demining and their solutions," in The Detection of Abandoned Land Mines: A Humanitarian Imperative Seeking a Technical Solution, Edinburgh, U.K., Oct. 1996, EUREL Int. Conf., UNOCHA Mine Clearance Program, pp. 1-5, Conf. Publ. No. 431

[7] H. Hambric and W. Schneck, "The antipersonnel mine threat," in Proc. Int. Symp. Technology and the Mine Problem, Monterey, CA, Nov. 1996, pp. 3-11.

[8] Levscan (Neutronbackscattered Techniques). Spot Level and Interface Measurements Plant Assessment Technology (PAT) Group, Industrial Technology Division, 2004 [Online]. Available: http://www.mint.gov.my/PRODUCTS/BTI/PAT/LEVSCAN.htm

[9] Level and Interface Measurement Nuclear Scanning Services Inc., 1997 [Online]. Available: http://www.nuclearscanning.com/neutron.htm

[10] Building Structures, Moisture Content: Neutron Method. NT Build346, Nordtest, 1998 [Online]. Available: http://www.nordicinnovation.net/ nordtestfiler/build346.pdf

[11] F. D. Brooks, A. Buffler, and S. M. Allie, "Detection of plastic landmines by neutron backscattering," presented at the 6th Int. Conf. Applications of Neutron Science, Crete, Greece, Jun. 1999.

[12] C. Datema, V. R. Bom, and C. W. E. van Eijk, "Land mine detection with the neutron back scattering method," IEEE Trans. Nucl. Sci., vol. 48, no. 4, pp. 1087-1091, Aug. 2001.

[13] C. Datema, V. R. Bom, and C. W. E. van Eijk, "DUNBLAD, the Delft University neutron backscattering landmine detector," presented at the 5th Int. Symp. Technology and the Mine Problem, Monterey, CA, Apr. 2002.

[14] G. Nebbia et al., "DIAMINE (detection and imaging of anti-personnel landmines by neutron backscattering technique)," presented at the 5th Int. Symp. Technology and the Mine Problem, Monterey, CA, Apr. 2002.

[15] J. Csikai, B. Király, and R. Dóczi, Application of Neutrons to Plastic Landmines Detection IAEA, Vienna, Austria, 2001, IAEA/PS/RC-799-2.
[16] V. R. Bom, C. W. E. van Eijk, A. M. Ali, A. M. Osman, A. M. A El-Monem, W. A. Kansouh, and R. M. Megahid, "A feasibility test of land mine detection in a desert environment using neutron back scattering imaging," IEEE Trans. Nucl. Sci., vol. 53, no. 4, pp. 2247-2251, Aug. 2006.

[17] V. R. Bom, C. W. van Eijk, and M. A. Ali, "Land mine detection with neutron back scattering imaging using a neutron generator," IEEE Trans. Nucl. Sci., vol. 53, no. 1, pp. 356-360, Feb. 2006.

[18] V. Joynt, " The stages of a mine clearance operation," presented at the 7th Int. Conf. Applications of Neutron Techniques, Crete, Greece, Jun. 2001.

[19] C. Datema, V. R. Bom, and C. W. E. van Eijk, "Monte Carlo simulations of landmine detection with neutron backscattering," 2000, Rep. ST-ISO-2000-015.

[20] G. Viesti et al., J. Duggan and I. Morgan, Eds., "The DIAMINE landmine detection system," in Proc. 17th Int. Conf. Application of Accelerators in Research and Industry, Denton, TX, Nov. 2002, pp. 924-927.

[21] J. Obhodas, D. Sudac, K. Nad, V. Valkovic, G. Nebbia, and G. Viesti, J. Duggan and I. Morgan, Eds., "The role of soil nbt applications to landmine detection problem," in Proc. 17th Int. Conf. Application of Accelerators in Research and Industry, Denton, TX, Nov. 2002, pp. 895-899.

[22] J. Obhodas, D. Sudac, K. Nad, V. Valkovic, G. Nebbia, and G. Viesti, "The soil moisture and its relevance to the landmine detection by neutron backscattering technique," Nucl. Instrum. Methods Phys. Res. B, vol. B213, pp. 445-451, Jan. 2004

[23] V. R. Bom, C. W. van Eijk, and M. A. Ali, "DUNBID, the Delft University neutron backscattering imaging detector," Appl. Radiat. Isot., vol. 63, no. 5-6, pp. 559-563, Nov./Dec. 2005.

[24] G. Turin, "An introduction to matched filters," IEEE Trans. Inf. Theory, vol. 6, pp. 311-329, Jun. 1960.

[25] C. Datema, V. R. Bom, and C. W. E. van Eijk, "Experimental results and Monte Carlo simulations of a land mine localization device using the neutron back scattering method," Nucl. Instrum. Methods Phys. Res. A, vol. A488, no. 1-2, pp. 441-450, Aug. 2002.

[26] G. Viesti, M. Lunardon, G. Nebbia, M. Barbui, M. Cinausero, G. D'Erasmo, M. Palomba, A. Pantaleo, J. Obhodas, and V. Valkovic, "The detection of landmines by neutron backscattering: Exploring the limits of the technique," Appl. Radiat. Isot., vol. 64, pp. 706-717, 2006

[27] "A study of manual mine clearance," Tech. Rep., Geneva International Centre for Humanitarian Demining (GICHD), 2005 [Online]. Available: http://www.itep.ws/pdf/Manual_Mine_Clearance_FullBook.pdf

[28] A. Smith, "Comparative trials of manual mine clearance techniques," Mozambique, Geneva International Center for Humanitarian Demining, 2004 [Online]. Available: http://www.itep.ws/pdf/AVS_Mozambique_comparative_trials_for_ITEPfin.pdf 